\title{
Custos na Administração Pública: revisão focada na publicação de artigos científicos a partir da promulgação da Lei de Responsabilidade Fiscal
}

\section{Costs in the Public Administration: review focused on publication of scientific papers from promulgation of Fiscal Responsibility Law}

\section{Alexandre de Freitas Carneiro}

Mestre em Administração pela Universidade Federal de Rondônia

Professor do Curso de Ciências Contábeis da Universidade Federal de Rondônia

Endereço: Rua Osvaldo Cruz, 725 - Bairro Centro

CEP: 76.980-000 - Vilhena/RO - Brasil

E-mail: alexandrevha@hotmail.com

Telefone: (69) 3322-7457 e (69) 9232-7496

\section{José Moreira da Silva Neto}

Doutor em Engenharia de Produção pela Universidade Federal de Santa Catarina (UFSC)

Professor do Programa de Pós-Graduação Mestrado em Administração da Universidade

Federal de Rondônia

Endereço: Rua Severino Silva, 3475 - Bairro Cuniã

CEP: 76.824-502 - Porto Velho/RO - Brasil

E-mail:msilva@unir.br

Telefone: (69) 3214-4193 e (69) 9984-4348

\section{Rosilene Locks}

Mestre em Administração pela Universidade Federal de Rondônia

Auditora de Tributos e Finanças do Estado de Rondônia

Professora do Curso de Ciências Contábeis da Universidade Federal de Rondônia

Endereço: Rua Cevanes Monteiro, 4611 - Bairro Rio Madeira

CEP: 76.821-350 - Porto Velho/RO - Brasil

E-mail: rosilenelocks7@ hotmail.com

Telefone: (69) 8111-5233

\section{Maria Madalena Alves dos Santos}

Mestre em Administração pela Universidade Federal de Rondônia

Auditora do Tesouro Municipal em Porto Velho - Rondônia

Endereço: Rua Joaquim Tanajura, no 4130 - Conjunto Santo Antônio, Bairro São João Bosco

CEP: 76803-798 - Porto Velho/RO - Brasil

E-mail: madalena.santos@ semfazonline.com

Telefone: (69) 3226-1378 e (69) 9982-1856

Artigo recebido em 16/12/2011. Revisado por pares em 06/08/2012. Reformulado em 21/08/2012. Recomendado para publicação em 05/10/2012 por Sandra Rolim Ensslin (Editora Científica). Publicado em 14/12/2012. 


\title{
Resumo
}

O objetivo principal deste trabalho é dimensionar e revisar de forma descritiva a produção científica sobre custos no setor público, no período de 2000 a 2010, nos anais eletrônicos dos eventos brasileiros da Associação Nacional de Pós-Graduação e Pesquisa em Administração (ANPAD), da Associação Brasileira de Custos (ABC) e do Congresso de Controladoria e Contabilidade da Universidade de São Paulo (USP). Essa revisão evidenciou que as técnicas de pesquisas mais utilizadas nas publicações foram as entrevistas e a análise documental e que o método de custeio mais discutido e sugerido para o setor público foi o Activity-Based Cost $(\mathrm{ABC})$.

Palavras-chave: Custos. Sistema de custos. Administração pública.

\begin{abstract}
The main objective of this work is to scale and do a descriptive review of the scientific literature on costs in the public sector, in the period from 2000 to 2010, in the electronic annals of Brazilian events of National Association of Postgraduate Studies and Research in Administration (Associação Nacional de Pós-Graduação e Pesquisa em Administração (ANPAD)), Brazilian Association of Costs (Associação Brasileira de Custos (ABC)) and Congress of Controlling and Accounting at the University of Sao Paulo (Congresso de Controladoria e Contabilidade da Universidade de São Paulo (USP)). This review revealed that the most used research techniques in publications were interviews and documentary analysis and that the most discussed and suggested costing method for the public sector was the Activity-Based Cost (ABC).
\end{abstract}

Keywords: Costs. Cost system. Public administration.

\section{Introdução}

As necessidades de alinhar-se aos padrões econômicos internacionais e de gerar mais benefícios sociais com menos recursos, de conviver cada vez mais com demandas sociais crescentes que implicam utilização de recursos escassos estão transformando, não somente as organizações orientadas para o mercado, mas também as organizações orientadas para o estado e para a sociedade civil. As decisões baseadas em custos e eficiência de recursos passaram, portanto, a ser imperativas para um bom processo de gestão, independente de qual seja a orientação da organização (pública, privada ou social).

No Brasil, principalmente nas duas últimas décadas, em termos de gestão e controle, este alinhamento está sendo chamado de harmonização. $\mathrm{O}$ foco inicial foi a área societária, mas rapidamente se percebeu a necessidade de abranger também as demais áreas (pública e sociais). Na área pública brasileira, essa convergência deverá ser implementada, inicialmente, na União, depois nos Estados e concluída nos Municípios, segundo o prazo estabelecido pela Secretaria do Tesouro Nacional (STN), até 2014. O intuito é padronizar e alinhar as normas brasileiras às normas internacionais de Contabilidade publicadas pela International

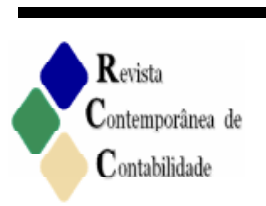


Federation of Accountants (IFAC). É uma reforma necessária para que as metas de desenvolvimento sejam atingidas (CHAN, 2010).

Visando ao alinhamento e à convergência às normas internacionais, o Conselho Federal de Contabilidade (CFC) elaborou e publicou, em 2008, a Norma Brasileira de Contabilidade Técnica 16 (NBC T 16), também conhecida como Normas Brasileiras de Contabilidade Aplicadas ao Setor Público (NBCASP). Com base nessas normas, em 2009 a STN editou o Manual de Contabilidade Aplicada ao Setor Público (MCASP), o qual terá vigência completa até o ano de 2013. Essas normas e manuais têm sido denominados de Nova Contabilidade Pública (NCP).

Uma exigência a ser implementada é o desenvolvimento de um sistema de custos. No entanto, o sistema de custo já havia sido ordenado pela Lei de Responsabilidade Fiscal (LRF), porém até o ano de 2009 soube-se muito pouco sobre o cumprimento de tal ordenamento (ALMEIDA; BORBA; FLORES, 2009).

O objetivo principal é dimensionar e revisar de forma descritiva a produção científica nos anais eletrônicos dos eventos brasileiros da Associação Nacional de Pós-Graduação e Pesquisa em Administração (ANPAD), Associação Brasileira de Custos (ABC) e do Congresso de Controladoria e Contabilidade da Universidade de São Paulo (USP). Desse modo, o delineamento da pesquisa foi sobre a produção científica acerca do tema Custos no Setor Público nos anais eletrônicos desses importantes eventos brasileiros da área, desde o período de implantação da LRF até o ano de início de implantação de forma facultativa das atuais Portarias da STN, ou seja, de maio de 2000 a dezembro de 2010, aproximadamente 11 anos. As questões norteadoras da pesquisa são: Quanto foi produzido? Quais são as áreas temáticas? Quais e quantos autores por trabalho e quantas instituições de filiação? Quais as técnicas e os métodos de pesquisa utilizados? Qual o método de custeio mais discutido? Qual a orientação ou discussão dos pesquisadores sobre o método de custeio mais adequado para o setor público?

Justifica-se a pesquisa devido aos prazos concedidos pelas normas da STN. Desse modo, os resultados da pesquisa podem demonstrar o estágio atual da produção científica antes da vigência completa desses prazos. Poderá, também, contribuir para os profissionais de Contabilidade do setor público no direcionamento de seus trabalhos. Pretende-se colaborar, ainda, com as discussões relacionadas à produção científica sobre a Contabilidade Pública.

Este trabalho está estruturado, além desta introdução, em outras cinco seções. $\mathrm{Na}$ seção 2, apresenta-se o referencial teórico da nova contabilidade pública e custos no setor público; na seção 3, trata-se dos procedimentos metodológicos; os resultados e a discussão da produção científica constam da seção 4; e as conclusões são apresentadas na seção 5.

\section{Referencial Teórico}

\subsection{A Nova Contabilidade Pública}

O grande marco histórico está na edição do que se tem chamado de Normas Brasileiras de Contabilidade Aplicadas ao Setor Público (NBCASP), em 2008. Esse processo foi o início da convergência com vistas a alinhar às Normas Internacionais de Contabilidade do Setor Público (International Public Sector Accounting Standard IPSAS), editadas pelo International Public Sector Accounting Standard Board (IPSASB) e 
publicadas pela IFAC. As ações em conjunto do CFC e STN podem ser consideradas um novo marco conceitual para uma nova contabilidade do setor público (ROSA, 2011). No Quadro 1, resumem-se algumas das novas exigências, como a obrigatoriedade de desenvolver um subsistema de custos.

Quadro 1 - Novas exigências no campo da Contabilidade Pública

\begin{tabular}{|c|c|c|}
\hline Contabilidade Pública antes & $\begin{array}{c}2008 \\
2010\end{array}$ & Nova Contabilidade Pública \\
\hline $\begin{array}{l}\text { Sistemas: Orçamentário, Financeiro } \\
\text { Patrimonial e Compensação }\end{array}$ & \multirow{6}{*}{$\begin{array}{l}\mathbf{N} \\
\mathbf{B} \\
\mathbf{C} \\
\mathbf{A} \\
\mathbf{S} \\
\mathbf{P}\end{array}$} & Incluído o Subsistema de Custos \\
\hline $\begin{array}{l}\text { Demonstrações Contábeis: Balanço } \\
\text { Orçamentário, Balanço Financeiro } \\
\text { Balanço Patrimonial e Demonstração } \\
\text { das Variações Patrimoniais }\end{array}$ & & $\begin{array}{l}\text { Incluídas as demonstrações: Demonstração dos Fluxos de } \\
\text { Caixa, Demonstração do Resultado Econômico e Notas } \\
\text { Explicativas }\end{array}$ \\
\hline Reavaliação & & Depreciação, Amortização e Exaustão \\
\hline Regime de Caixa e de Competência & & Regime de Competência \\
\hline Ativo Financeiro e Ativo Permanente & & $\begin{array}{l}\text { Grupo Contábil Ativo Intangível } \\
\text { Ajuste a Valor Presente } \\
\text { Redução ao Valor Recuperável (Impairment) }\end{array}$ \\
\hline Demais anexos da Lei n. 4.320 e LRF & & Demonstrativo de Estatística de Finanças Públicas \\
\hline
\end{tabular}

Fonte: Elaboração própria com base nas Resoluções do CFC de 2008 e Portarias da STN de 2010.

Com a nova Contabilidade Pública, passarão a ser adotados dois regimes contábeis simultaneamente: um orçamentário (misto), conforme a Lei n. 4.320/1964, e outro patrimonial (competência), conforme as NBCASP.

Os princípios de Contabilidade foram interpretados sob a perspectiva do setor público, no ano de 2007, com a publicação da Resolução n. 1.111 do CFC. Para Silva (2011, p. 355), "a edição dos princípios fundamentais de contabilidade sob a perspectiva do setor público e das Normas Brasileiras de Contabilidade Aplicadas ao Setor Publico representa uma nova etapa da contabilidade pública". Essa nova etapa representa outro marco na história da Contabilidade governamental no Brasil após a LRF, a qual foi também um marco histórico.

O termo Nova Contabilidade Pública (NCP) surgiu tendo em vista as novas normas e manuais editados pelos respectivos órgãos competentes. A NBC T 16, editada pelo CFC e publicada em 21 de novembro de 2008, por meio das Resoluções do CFC de n. 1.128 a n. 1.137, compõe-se de 10 normas. Essas normas tornaram-se obrigatórias a partir de $1^{\circ} \mathrm{de}$ janeiro de 2010 e, em 2011, foi incluída a Resolução CFC n. 1.366. No Quadro 2, as normas estão relacionadas com as respectivas resoluções e conteúdo.

Quadro 2 - Normas brasileiras de Contabilidade aplicadas ao Setor Público

\begin{tabular}{|l|c|l|}
\hline \multicolumn{1}{|c|}{ NORMA } & RESOLUÇÃO & \multicolumn{1}{c|}{ CONTEÚDO } \\
\hline NBC T 16.1 & $1.128 / 08$ & Conceituação, Objetivo e Campo de Aplicação \\
\hline NBC T 16.2 & $1.129 / 08$ & Patrimônio de Sistemas Contábeis \\
\hline NBC T 16.3 & $1.130 / 08$ & Planejamento e seus instrumentos sob o Enfoque Contábil \\
\hline NBC T 16.4 & $1.131 / 08$ & Transações no Setor Público \\
\hline NBC T 16.5 & $1.132 / 08$ & Registro Contábil \\
\hline
\end{tabular}


Custos na Administração Pública: revisão focada na publicação de artigos científicos a partir da...

\begin{tabular}{|l|l|l|}
\hline NBC T 16.6 & $1.133 / 08$ & Demonstrações Contábeis \\
\hline NBC T 16.7 & $1.134 / 08$ & Consolidação das Demonstrações Contábeis \\
\hline NBC T 16.8 & $1.135 / 08$ & Controle Interno \\
\hline NBC T 16.9 & $1.136 / 08$ & Depreciação, Amortização e Exaustão \\
\hline NBC T 16.10 & $1.137 / 08$ & $\begin{array}{l}\text { Avaliação e Mensuração de Ativos e Passivos em Entidades do } \\
\text { Setor Público }\end{array}$ \\
\hline NBC T 16.11 & $1.166 / 08$ & Sistema de Informação de Custos do Setor Público \\
\hline
\end{tabular}

Fonte: Elaboração própria com base nas normas do Conselho Federal de Contabilidade (CFC) (www.cfc.org.br).

Em 2009, por meio de várias portarias publicadas em agosto e dezembro, a STN, em trabalho conjunto com a Secretaria de Orçamento Federal (SOF), nas Partes I e VIII, elaboraram o Manual de Contabilidade Aplicada ao Setor Público MCASP. Esse Manual será aplicado obrigatoriamente pela União, pelos Estados, pelo Distrito Federal e pelos Municípios. No ano de 2010, a aplicação foi de forma facultativa, porém é obrigatória em 2011 para a União, em 2012 para os Estados e Distrito Federal, e em 2013 para os Municípios.

Em novembro de 2011, o CFC incluiu a norma NBC T 16.11 Sistema de Informação de Custos do Setor Público (SICSP), por meio da Resolução n. 1.366/11, cujos objetivos são:

(a) mensurar, registrar e evidenciar os custos dos produtos, serviços, programas, projetos, atividades, ações, órgãos e outros objetos de custos da entidade;

(b) apoiar a avaliação de resultados e desempenhos, permitindo a comparação entre os custos da entidade com os custos de outras entidades públicas, estimulando a melhoria do desempenho dessas entidades;

(c) apoiar a tomada de decisão em processos, tais como comprar ou alugar, produzir internamente ou terceirizar determinado bem ou serviço;

(d) apoiar as funções de planejamento e orçamento, fornecendo informações que permitam projeções mais aderentes à realidade com base em custos incorridos e projetados;

(e) apoiar programas de redução de custos e de melhoria da qualidade do gasto.

O SICSP deve estar integrado com o processo de planejamento e orçamento e fazer da informação de custos um vetor de alinhamento e aperfeiçoamento do planejamento e orçamento futuros.

Convêm destacar a publicação da Resolução STN n. 828 em 14 de dezembro de 2011, a qual "Altera o prazo de implementação do Plano de Contas Aplicado ao Setor Público e dá outras providências". Tal norma altera a Portaria n. 406, de 20 de junho de 2011 e, com isso, os municípios tiveram prazo prorrogado, antes de 2013, agora 2014, para implementar sistema de custos. Destaca-se, ainda, que deverão publicar em meio eletrônico e enviar ao Tribunal de Contas o respectivo cronograma de adoção dos aspectos patrimoniais constantes do MCASP.

$\mathrm{Na}$ segunda edição, o Manual de Contabilidade Aplicado ao Setor Público foi composto por cinco volumes, mas, na terceira edição, editada em novembro de 2010, foi divido em partes. A quarta edição foi publicada em junho de 2011. As partes do Manual, seus títulos e a legislação respectiva estão descritos no Quadro 3. 


\begin{tabular}{|c|c|c|}
\hline \multicolumn{3}{|c|}{ Quadro 3 - Partes do MCASP } \\
\hline PARTES & PORTARIA & TÍTULOS \\
\hline Parte I & $\mathrm{STN} / \mathrm{SOF} \mathrm{n}^{\circ} 1 / 11$ & Procedimentos Contábeis Orçamentários \\
\hline Parte II & $\mathrm{STN} \mathrm{n}^{\circ} 406 / 11$ & Procedimentos Contábeis Patrimoniais \\
\hline Parte III & $\mathrm{STN} \mathrm{n}^{\circ} 406 / 11$ & Procedimentos Contábeis Específicos \\
\hline Parte IV & $\mathrm{STN} \mathrm{n}^{\circ} 406 / 11$ & Plano de Contas Aplicado ao Setor Público \\
\hline Parte V & $\mathrm{STN} \mathrm{n}^{\circ} 406 / 11$ & Demonstrações Contábeis Aplicadas ao Setor Público \\
\hline Parte VI & STN n $^{\circ} 406 / 11$ & Perguntas e Respostas \\
\hline Parte VII & $\mathrm{STN} \mathrm{n}^{\circ} 406 / 11$ & Exercício Prático \\
\hline Parte VIII & $\mathrm{STN} / \mathrm{SOF} \mathrm{n}^{\circ} 1 / 11$ & Demonstrativo de Estatística de Finanças Públicas \\
\hline
\end{tabular}

Fonte Elaboração própria com base nas Portarias da STN e SOF de 2011.

Os objetivos das Partes são estas: a promoção da transparência das contas públicas, a padronização de procedimentos e a consolidação das contas públicas (ROSA, 2011).

\subsection{Custos no Setor Público}

O ordenamento sobre custos na gestão pública não é recente, pois a Lei n. 4.320, de 1964, no art. 85, expressa, entre outros itens, "a determinação dos custos dos serviços industriais". Três anos depois, o Decreto-Lei n. 200/67 ordenou sobre a apuração de custos, mas somente no âmbito da administração pública federal.

Dez anos após a promulgação a Constituição Federal (CF), de 1988, a Emenda Constitucional n. 19/98 dispôs sobre princípios e normas de gestão pública e exigiu o controle das finanças públicas. De acordo com a nova redação dada por essa Emenda, foi incluído o princípio da eficiência no art. $37 \mathrm{da} \mathrm{CF}$. Esse princípio foi claramente definido pela GESPÚBLICA da seguinte forma: "Eficiência: fazer o que precisa ser feito com a máxima qualidade ao menor custo possível. Não se trata de redução de custo de qualquer maneira, mas de buscar a melhor relação entre qualidade do serviço e qualidade do gasto" (BRASIL, 2008, p. 10). A relação entre eficiência e qualidade é estreita. Reduzir custos sem critérios não significa ser eficiente. Na opção por redução de custos, é necessário ou uma preservação ou mesmo alguma melhora na qualidade (CRUZ; PLATT NETO, 2007).

A Lei de Responsabilidade Fiscal evidenciou a finalidade de um sistema de custos, no art. 50, ao determinar que a "Administração Pública manterá sistema de custo que permita a avaliação e o acompanhamento da gestão orçamentária, financeira e patrimonial”. Segundo Silva et al. (2007, p. 14), "com o advento da LRF, em 2000, a mesma reconheceu a fragilidade da Administração Pública quando trouxe regra, demonstrando nitidamente que não há controle de custo no governo, tão pouco avaliação dos resultados". Uma falha dessa norma, e das anteriores, foi o fato de não estabelecer prazo para implementar e desenvolver sistema de custos no setor público. Alonso (1999) afirma que "não existe uma cultura de custos no serviço público brasileiro. Ainda segundo esse autor, se não há medição de custos, também não haverá medida de eficiência, pois esta é a relação entre os resultados e o custo para obtêlos" (ALONSO, 1999, p. 44).

A Parte V do MCASP ressalta que "a maioria dos gestores não sabem dizer se as ações oferecidas à sociedade são bem sucedidas ou não", e mostra um exemplo no caso de quando há cortes no orçamento, "não sabem se estão cortando 'supérfluos' ou 'essenciais', devido à falta de informações objetivas quanto aos resultados alcançados". O governo não tem conhecimento sobre desperdícios e onde há eficiência no uso dos recursos (LUQUE et al., 2008, p. 317).

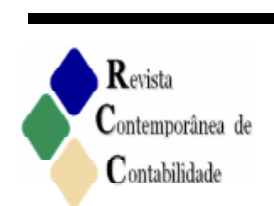


Sem um adequado controle por meio de um sistema de custos, a apuração de resultados e a produção de informações econômico-financeiras e relatórios de desempenho seriam ineficientes.

\subsubsection{Métodos de Custeio no Setor Público}

As formas de custeio ou métodos de custeio correspondem à forma de apropriação dos custos. Na Parte II do MCASP estão elencadas cinco formas de custeio: Custeio por Absorção; Custeio Pleno; Custeio ABC (Activity Based Cost - Custeio Baseado em Atividades); Custeio Variável; Custeio por Ordem de Produção; e Custeio por Processo (p. 122). Na administração pública dos EUA, generalizou-se o uso do $\mathrm{ABC}$ com o governo Clinton (ALONSO, 1999).

Nelson Machado (2002) aponta os principais métodos: Custeio por Absorção; Custeio Pleno; Custeio por Atividades; Custeio Variável; e Custeio Direto. Para o autor, a "escolha do método de custeio do setor público não é tarefa fácil" (p. 148), mas esses cinco modelos poderiam ser adotados. Porém discute o método de custeio direto no setor público, custeio por atividades no setor público e gestão por resultados. Em pesquisa mais recente, Söthe et al. (2010) destacaram os métodos aplicáveis nas entidades do setor público: custeio por absorção, custeio baseado em atividades e custeio pleno.

\subsubsection{Sistemas de Custos no Setor Público}

A NBC T 16.2 (2008) refere-se ao sistema contábil do qual faz parte o sistema de custos que, segundo a norma, "registra, processa e evidencia os custos dos bens e serviços, produzidos e ofertados à sociedade pela entidade pública". Para complementar a norma, o sistema de custos deve servir de suporte ao processo decisório, mais do que apenas cumprimento da legalidade. Segundo Martins (2006, p. 21), "a contabilidade de custo tem duas funções relevantes: o auxílio ao controle e a ajuda às tomadas de decisão".

Cruz e Platt Neto ensinam sobre as características e as novas perguntas que um sistema de custos deve se propor a responder, descritas no Quadro 4.

Quadro 4 - Características e perguntas a serem respondidas por um sistema de custos

\begin{tabular}{|l|ll|}
\hline \multicolumn{1}{|c|}{ CARACTERÍSTICAS } & \multicolumn{1}{|c|}{ PERGUNTAS } \\
\hline 1) É algo dinâmico, 2) Está em constante evolução, & 1) Onde custou? & 2) Como custou? \\
3) Não é algo estático, 4) Flexibilidade, & 3) Quanto custou? & 4) Quem comprou? \\
5) Adaptável à realidade do ente público & 5) O que comprou? & 6) Por que comprou? \\
6) A informação isolada “o quanto custou”, não & & \\
auxilia muito na tomada de decisão & & \\
\hline
\end{tabular}

Fonte: Adaptado de Cruz e Platt Neto (2007, p. 72-73).

As informações produzidas por um sistema de custos serviriam também ao estabelecimento de prioridades e eliminação de atividades que não adicionam valor (ATKINSON et al., 2008).

Lima e Castro (2003, p. 237) afirma que "por meio de um sistema de custo e adotado um método adequado, o cidadão saberia, por exemplo, o custo para os cofres públicos de determinado serviço ou produto [...]". Porém Slomski (2007) argumenta sobre a assimetria 
entre as informações produzidas pela administração pública e a sociedade. O poder público informa, porém o cidadão não entende o que é informado.

Sob esse enfoque, a finalidade do sistema de custos serviria para promover o controle social. Os gestores públicos devem evidenciar em suas prestações de contas os resultados físicos, financeiros e econômicos para promover não só a transparência, mas também o controle social das contas públicas. Para Mutula e Wamukoya (2009), o acesso efetivo, a gestão e exploração de informação oficial são os meios pelos quais governos podem demonstrar accountability e transparência no uso de recursos públicos, e também melhorarem a entrega de serviços.

Na Contabilidade Pública, antes das publicações dos manuais da STN, os sistemas eram estanques, ou seja, contas contábeis movimentavam-se umas contra as outras do mesmo sistema. Mauss e Souza (2008) demonstram os subsistemas da Contabilidade Financeira e Gerencial da seguinte forma:

Figura 1 - Sistemas na área da Contabilidade Pública

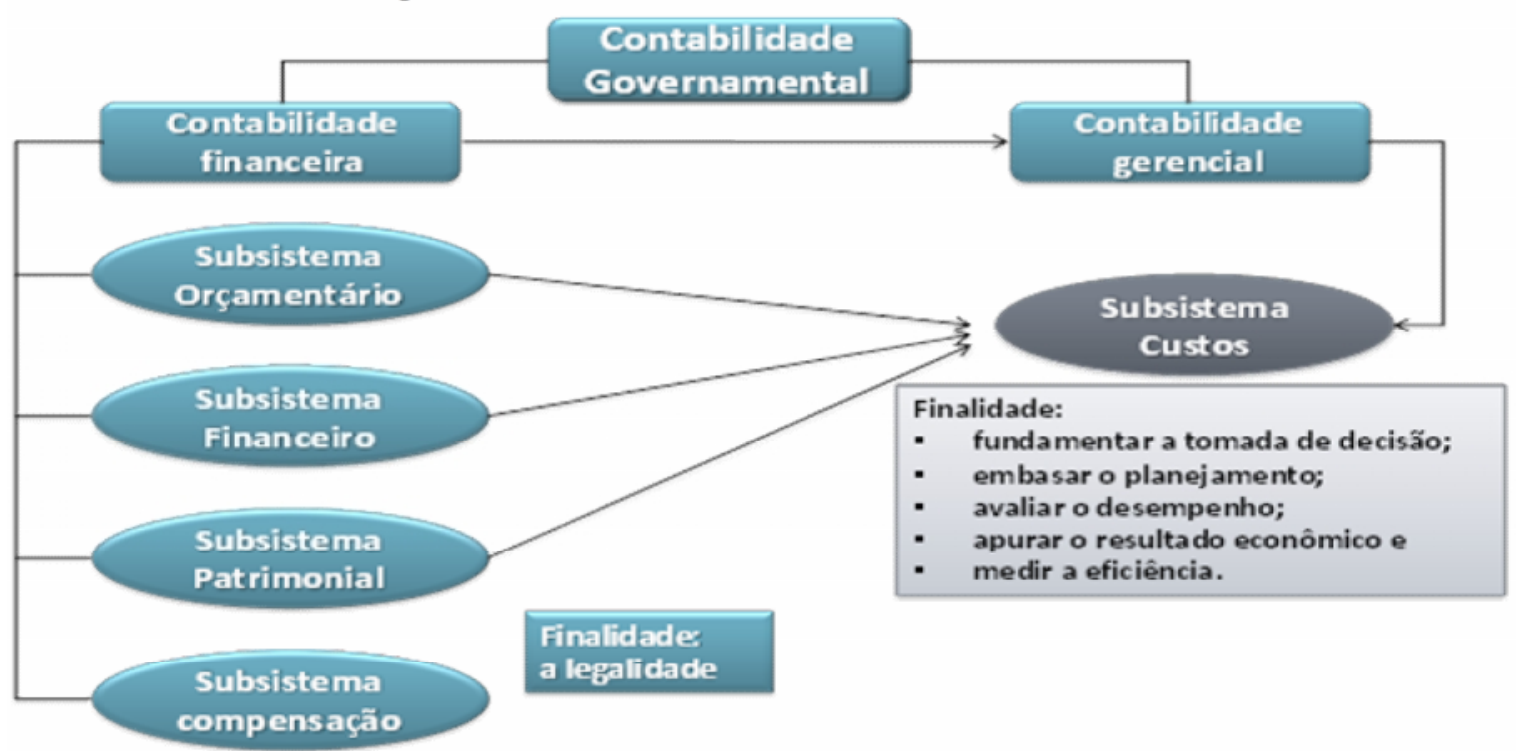

Fonte: Mauss e Souza (2008, p. 8).

Os subsistemas orçamentário, financeiro e patrimonial são alimentadores do subsistema de custos. No entanto, houve mudanças com a terceira edição do MCASP em 2010. Com a quarta edição, conforme a Portaria n. 406/2011, na Parte IV - Plano de Contas Aplicado ao Setor Público, os sistemas foram reestruturados, conforme o Quadro 5.

Quadro 5 - Subsistemas com base na nova Contabilidade Pública

\begin{tabular}{|c|c|}
\hline SUBSISTEMAS & DESCRIÇÃO \\
\hline $\begin{array}{l}\text { Subsistema de } \\
\text { Informações } \\
\text { Orçamentárias }\end{array}$ & $\begin{array}{l}\text { Registra, processa e evidencia os atos e os fatos relacionados ao } \\
\text { planejamento e à execução orçamentária, tais como: Orçamento; } \\
\text { Programação e execução orçamentária; Alterações orçamentárias; e } \\
\text { Resultado orçamentário. }\end{array}$ \\
\hline $\begin{array}{l}\text { Subsistema de } \\
\text { Informações } \\
\text { Patrimoniais }\end{array}$ & $\begin{array}{l}\text { Registra, processa e evidencia os fatos financeiros e não financeiros } \\
\text { relacionados com as variações do patrimônio público, subsidiando a } \\
\text { administração com informações tais como: Alterações nos elementos } \\
\text { patrimoniais; Resultado econômico; e Resultado nominal. }\end{array}$ \\
\hline
\end{tabular}

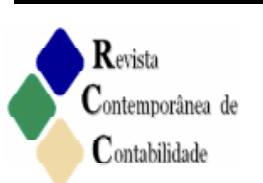




\begin{tabular}{|c|l|}
\hline Subsistema de Custos & $\begin{array}{l}\text { Registra, processa e evidencia os custos da gestão dos recursos e do } \\
\text { patrimônio público, subsidiando a administração com informações tais } \\
\text { como: Custos dos programas, dos projetos e das atividades desenvolvidas; } \\
\text { Bom uso dos recursos públicos; e Custos das unidades contábeis. }\end{array}$ \\
\hline $\begin{array}{c}\text { Subsistema de } \\
\text { Compensação }\end{array}$ & $\begin{array}{l}\text { Registra, processa e evidencia os atos de gestão cujos efeitos possam } \\
\text { produzir modificações no patrimônio da entidade do setor público, bem } \\
\text { como aqueles com funções específicas de controle, subsidiando a } \\
\text { administração com informações tais como: Alterações potenciais nos } \\
\text { elementos patrimoniais, e Acordos, garantias e responsabilidades. }\end{array}$ \\
\hline
\end{tabular}

Fonte: Adaptado do Manual de Contabilidade Aplicado ao Setor Público, Parte IV (2011, p. 13).

O Subsistema de Informações Patrimoniais passou a englobar os registros, o processamento e a evidenciação de fatos tanto financeiros como não financeiros. Foi extinto o Sistema Financeiro, e o Subsistema de Custo passa a ser oficializado.

À luz dos dispositivos legais e da doutrina discutidos, é oportuno afirmar que os gestores públicos não podem mais protelar a implantação e o desenvolvimento de um eficiente subsistema de custos.

Sobre os resultados de pesquisas anteriores, destacam-se quatro: duas com a constatação da baixa ou relativamente baixa participação do tema Contabilidade Pública em eventos (GOMES et al., 2008; REIS et al., 2007), uma sobre custos na área pública, a qual mostrou que "ainda é um tema pouco abordado" (ALMEIDA; BORBA; FLORES, 2009, p. 580 ), e em outra, foi concluído que grande parte dos estados brasileiros ainda não tem sistema de custos (SOUZA et al., 2006).

\section{Procedimentos Metodológicos}

Esta pesquisa-revisão tem natureza descritiva. Vergara (2009) considera a classificação da pesquisa científica em dois aspectos: quantos aos fins e quanto aos meios. Quanto aos fins, classifica-se como exploratória porque foi realizada em área na qual há pouco conhecimento acumulado e sistematizado, e quanto aos meios é classificada como bibliográfica. Segundo Gil (2008), na pesquisa bibliográfica, ou pesquisa exploratória, os objetivos precisam proporcionar mais familiaridade com o problema e aprimoramento de ideias. Justifica-se uma abordagem predominantemente qualitativa pelo fato de a preocupação ser a interpretação em vez de medição (MARTINS; THEÓPHILO, 2007).

A base de dados da pesquisa é composta por artigos científicos publicados em três eventos: dois da ANPAD e um da $\mathrm{ABC}$ com o tema custos no setor público. A análise compreendeu o período desde janeiro de 2000, ano de vigência da LRF, até dezembro de 2010, ano de aplicação facultativa das portarias da STN. A escolha dos períodos justificou-se por ser um marco na Contabilidade do setor público. O período de realização da pesquisa foi de março a junho de 2011.

Os artigos pesquisados foram os publicados on-line na página do Encontro Nacional dos Programas de Pós-Graduação em Administração (EnANPAD), na página do Encontro Nacional de Administração Pública e Governança (EnAPG), na página da Associação Brasileira de Custos (ABC) que publica todos os artigos apresentados no Congresso Brasileiro de Custos (CBC) e na página da USP, especificamente nos anais do Congresso de Controladoria e Contabilidade. 
Utilizaram-se para a identificação dos artigos relacionados ao tema as palavras-chave: "custos", "custo", "sistema de custos", "contabilidade de custos", "administração pública" e "setor público". Foram consideradas importantes essas palavras-chave para assegurar todas as possibilidades de identificação dos artigos.

Com relação aos procedimentos para identificação dos artigos, inicialmente tentou-se localizar pelo sistema de busca (Pesquisa) os trabalhos relacionados com o tema e após a leitura dos títulos, resumos e introdução que tivessem as palavras-chave, e em seguida realizou-se uma triagem, com leitura de objetivos e metodologia. Os artigos selecionados passaram por uma análise descritiva com base nos seguintes critérios:

- Qual o perfil da produção científica: quanto foi produzido; quais são as áreas temáticas; quais e quantos autores por trabalho e instituições de filiação; quais as técnicas e os métodos de pesquisa utilizados.

- O que tem sido escrito pelos pesquisadores sobre o tema.

- Qual a abordagem de método de custeio mais discutido.

- Qual a orientação ou discussão dos pesquisadores sobre o método de custeio mais adequado para o setor público, bem como sobre sistema de custos.

Os eventos da ANPAD, da ABC e da USP foram escolhidos por abranger as áreas temáticas relacionadas ao tema de pesquisa, bem como a tradição científica. É importante salientar que o evento EnAPG foi originado do EnANPAD e iniciado em 2004, como consta na página eletrônica. O Congresso Brasileiro de Custos começou em 1994 e é o principal divulgador da produção técnico-científica da especialidade e áreas afins, proporcionando a interação da comunidade acadêmica, de pesquisadores, de professores e de estudantes com empresários, consultores, contadores, administradores e demais profissionais atuantes na área da Gestão Estratégica de Custos. O Congresso de Controladoria e Contabilidade de USP teve início em 2001.

A pesquisa apresentou limitações devido à escolha das publicações a pesquisar. Os anais da produção científica do EnAPG, iniciados de forma eletrônica em 2004 e com periodicidade de dois em dois anos, somaram quatro encontros. O EnANPAD é anual e seus anais eletrônicos datam de 1997, mas o período de consulta foi a partir de 2000 e somou 11 encontros. O Congresso Brasileiro de Custos também possui periodicidade anual e nesta pesquisa foram selecionados os últimos 11 anos, totalizando também 11 congressos. Embora o Congresso de Controladoria e Contabilidade da USP tenha iniciado em 2001, as publicações somente estão disponíveis a partir de 2004.

\section{Resultados da Pesquisa}

Conforme os critérios pré-estabelecidos, os resultados foram apresentados acompanhados da discussão. Primeiro, é importante destacar que o total de trabalhos identificados com relação ao tema Custos no Setor Público foram 54 entre os vários trabalhos enumerados na página eletrônica da ANPAD, da ABC (CBC) e da USP com as palavraschave. Na Tabela 1, procurou-se evidenciar essa relação e a quantidade baixa de trabalhos científicos sobre o tema nos eventos escolhidos, ao se considerar um período de aproximadamente 11 anos: 
Tabela 1 - Artigos identificados por palavras-chave

\begin{tabular}{lcc}
\hline PALAVRAS-CHAVE & $\begin{array}{c}\text { Artigos } \\
\text { Enumerados }\end{array}$ & $\begin{array}{c}\text { Artigos } \\
\text { Identificados }\end{array}$ \\
\hline Custos & 693 & 20 \\
Custo & 361 & 4 \\
Sistema de Custos & 34 & 4 \\
Contabilidade de Custos & 46 & 13 \\
Administração Pública & 393 & 8 \\
Setor Público & 84 & 5 \\
\hline
\end{tabular}

Fonte: Dados da pesquisa (2011).

\subsection{Perfil da Produção Científica}

Nesta seção, são analisados o número de trabalhos publicados por ano e evento, as áreas temáticas, o número de autores por trabalho, os autores com maior número de publicações, a distribuição do total publicado por sexo pelas instituições, os métodos e as técnicas de pesquisa utilizados nos trabalhos.

Na Tabela 2, estão distribuídos os artigos publicados nos eventos e por ano:

\begin{tabular}{ccccccc}
\multicolumn{7}{c}{ Tabela 2 - Número de trabalhos por ano e evento } \\
\hline ANO & EnANPAD & EnAPG & CBC & USP & Total & \% \\
\hline 2000 & & & 3 & & 3 & 5,56 \\
2001 & & 1 & & 1 & 1,85 \\
2002 & & 1 & & 1 & 1,85 \\
2003 & 2 & & 2 & & 4 & 7,41 \\
2004 & 2 & 1 & 1 & 3 & 7 & 12,96 \\
2005 & 2 & & 3 & 1 & 6 & 11,11 \\
2006 & 1 & 2 & 5 & 2 & 10 & 18,52 \\
2007 & 1 & & 5 & 1 & 7 & 12,96 \\
2008 & 1 & & 4 & 2 & 7 & 12,96 \\
2009 & 1 & & 3 & & 3 & 5,56 \\
2010 & 1 & & 4 & & 5 & 9,26 \\
\hline Total & 10 & 3 & 32 & 9 & 54 & 100 \\
\hline
\end{tabular}

Fonte: Dados da pesquisa (2011).

O Congresso Brasileiro de Custos conta com o maior número de participações, pois ocorre todo ano. De 2000 a 2005 observa-se que os trabalhos sobre custos no setor público apresentaram uma tímida participação, porém, a partir de 2006, foram identificados 21 artigos.

O evento EnAPG tem a periodicidade de dois em dois anos e apresenta o menor número de publicações relativas ao objeto da pesquisa. Em seguida, o Congresso de Controladoria e Contabilidade da USP apresenta o segundo menor número de publicações e justifica-se pelo fato de que não estão disponíveis para consulta as publicações dos exercícios de 2000 a 2003, e nos exercícios de 2009 e 2010 não foi publicado nenhum trabalho sobre o assunto objeto da pesquisa. Os anos com maiores publicações, considerando os quatro eventos, foram 2004 e 2006, somando 17 trabalhos.

As áreas temáticas classificadas no EnANPAD estão demonstradas na Tabela 3. O EnAPG não apresenta nas informações do artigo aprovado e publicado a área temática 
relacionada, mas, a partir da edição de 2010, na página do evento, o link Temas de Interesse apresenta as áreas temáticas organizadas, numeradas e com líderes.

Tabela 3 - Áreas temáticas classificadas no EnANPAD

\begin{tabular}{|c|c|c|c|c|c|c|c|c|}
\hline ÁREA & 2003 & 2004 & 2005 & 2006 & 2007 & 2008 & 2010 & Total \\
\hline Contabilidade e Controle Gerencial & 1 & 1 & & & & & & 2 \\
\hline Contabilidade Gerencial e Controladoria & & & 2 & 1 & & & & 3 \\
\hline Gestão Pública e Governança & 1 & & & & & & & 1 \\
\hline Políticas Públicas & & 1 & & & & & & 1 \\
\hline Contabilidade Gerencial & & & & & 1 & & & 1 \\
\hline Gestão e Políticas Públicas & & & & & & 1 & & 1 \\
\hline Contabilidade Governamental e Terceiro & & & & & & & & \\
\hline Setor & & & & & & & 1 & 1 \\
\hline Total & 2 & 2 & 2 & 1 & 1 & 1 & 1 & 10 \\
\hline
\end{tabular}

Fonte: Dados da pesquisa (2011).

A área temática com maior frequência é Contabilidade Gerencial e Controladoria. Podem ter ocorrido mudanças, renome ou divisões nas áreas, porém predomina a Contabilidade Gerencial com seis trabalhos considerando três áreas com nomes semelhantes.

A Tabela 4 apresenta os artigos disponibilizados no Congresso Brasileiro de Custos por área temática. O CBC distribuiu os trabalhos, a partir de 2005, em 16 áreas temáticas, no entanto observa-se que, em 2000, esse quantitativo era de 30 áreas, separadas por área de atuação e até mesmo por segmento de negócios.

Tabela 4 - Áreas temáticas classificadas no Congresso Brasileiro de Custos

\begin{tabular}{|c|c|c|c|c|c|c|c|c|c|c|c|c|}
\hline ÁREA & 2000 & 2001 & 2002 & 2003 & 2004 & 2005 & 2006 & 2007 & 2008 & 2009 & 2010 & Total \\
\hline Gestão de Custos no Setor & & & & & & & & & & & & \\
\hline Governamental & & & & & & 3 & 4 & 5 & 4 & 3 & 4 & 23 \\
\hline Ensino e Pesquisa na Gestão & & & & & & & & & & & & \\
\hline de Custos & & & & & & & 1 & & & & & 1 \\
\hline Gestão de Custos no Setor & & & & & & & & & & & & \\
\hline Público & & & & 2 & 1 & & & & & & & 3 \\
\hline $\begin{array}{l}\text { Gestão de Custos e Sistema } \\
\text { de Informacão }\end{array}$ & & & 1 & & & & & & & & & 1 \\
\hline A Mensuração e Gestão de & & & & & & & & & & & & \\
\hline Custos no Setor Público & & 1 & & & & & & & & & & 1 \\
\hline Setor Público & 2 & & & & & & & & & & & 2 \\
\hline Seção de Estudantes & 1 & & & & & & & & & & & 1 \\
\hline Total & 3 & 1 & 1 & 2 & 1 & 3 & 5 & 5 & 4 & 3 & 4 & 32 \\
\hline
\end{tabular}

Fonte: Dados da pesquisa (2011).

A área de maior frequência para o Congresso Brasileiro de Custos é a Gestão de Custos no Setor Governamental, com 23 trabalhos, seguido da Gestão de Custos no Setor Público, com três trabalhos, tendo em vista a restrição do Congresso de apenas publicar artigos ligados à Contabilidade de Custos.

A Tabela 5 apresenta os artigos publicados no Congresso de Controladoria e Contabilidade da USP. Desde o início das publicações os trabalhos são classificados em cinco áreas temáticas específicas e, na Tabela 5, somente estão identificadas as áreas temáticas com publicações no período pesquisado.

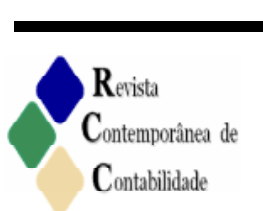


Tabela 5 - Áreas temáticas no Congresso da USP de Controladoria e Contabilidade

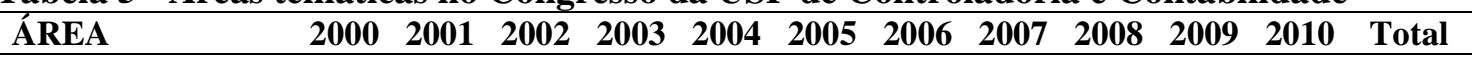

Controladoria e Contabilidade

Gerencial

Temas Emergentes em

Contabilidade

Contabilidade Aplicada para

Usuários Externos

$\begin{array}{lllllll}1 & 1 & 1 & 1 & 4\end{array}$

$\begin{array}{lllllll}1 & 1 & 1 & 1 & 4\end{array}$

Pesquisa e Ensino da

\begin{tabular}{lllllll} 
Contabilidade & 1 & & 1 \\
\hline Total & 3 & 1 & 2 & 1 & 2 & 9 \\
\hline
\end{tabular}

Fonte: Dados da pesquisa (2011).

Considerando o objetivo da pesquisa, a área de maior frequência para o Congresso da USP é Controladoria e Contabilidade Gerencial, com quatro trabalhos, seguido de Temas Emergentes e Contabilidade, com três trabalhos.

Nas Tabelas 6 e 7, estão demonstrados, respectivamente, os números de autores por trabalho aprovado e publicado e de autores com maior frequência de publicações. Pode-se observar que predominam trabalhos com quatro autores para os eventos EnANPAD e EnAPG. No evento EnANPAD, esses trabalhos representaram 40\%, e no evento, EnAPG 67\%. Em segundo lugar, estão os trabalhos com três autores com $40 \%$ também no EnANPAD. No Congresso Brasileiro de Custos (CBC), a maior frequência é de dois autores, representando $41 \%$ do total, seguido de trabalhos com três autores com 28\%. No Congresso de Controladoria e Contabilidade da USP, predominaram os trabalhos com dois autores, que representam $67 \%$ do total, seguidos de trabalhos com quatro autores, que representam $33 \%$.

Tabela 6 - Número autores por trabalho

\begin{tabular}{|c|c|c|c|c|c|c|c|c|}
\hline \multirow{2}{*}{$\begin{array}{c}\mathbf{N}^{0} \text { de } \\
\text { Autores }\end{array}$} & \multicolumn{2}{|c|}{ EnANPAD } & \multicolumn{2}{|c|}{ EnAPG } & \multicolumn{2}{|c|}{$\mathrm{CBC}$} & \multicolumn{2}{|c|}{ USP } \\
\hline & Trabalhos & Percentual & Trabalhos & Percentual & Trabalhos & Percentual & Trabalhos & Percentual \\
\hline 1 & 1 & 10 & 1 & 33 & 4 & 12 & & \\
\hline 2 & & & & & 13 & 41 & 6 & 67 \\
\hline 3 & 4 & 40 & & & 9 & 28 & & \\
\hline 4 & 4 & 40 & 2 & 67 & 6 & 19 & 3 & 33 \\
\hline 5 & 1 & 10 & & & & & & \\
\hline Total: & 10 & $100 \%$ & 3 & $100 \%$ & 32 & $100 \%$ & 9 & $100 \%$ \\
\hline
\end{tabular}

Fonte: Dados da pesquisa (2011).

O pesquisador Wellington Rocha é o autor que apresenta o maior número de publicações com seis trabalhos. O pesquisador Antônio Artur de Souza aparece em segundo lugar com quatro trabalhos. Os autores Charles, Robson, Simone Letícia Raimundini, Valmor Slomski e André Graf de Almeida encontram-se empatados com três trabalhos publicados cada um, conforme a Tabela 7.

Tabela 7 - Autores com maior número de publicações

\begin{tabular}{lcc}
\hline PESQUISADOR & Instituição & $\begin{array}{c}\mathbf{N}^{\mathbf{0}} \mathbf{d e} \\
\text { Trabalhos }\end{array}$ \\
\hline Wellington Rocha & USP & 6 \\
Antônio Artur de Souza & FGV & 4 \\
Charles Albino Schultz & UFSC & 3 \\
Valmor Slomski & USP & 3 \\
Robson Zucollato & UFV & 3 \\
\hline
\end{tabular}




\begin{tabular}{lcc}
\hline Simone Letícia Raimundini & UEM & 3 \\
André Graf de Almeida & UFSC & 3 \\
Carlos Alberto Diehl & ULBRA & 3 \\
José Roberto de Souza Blaschek & UERJ & 2 \\
Mirian Aparecida Micarelli Struett & UEM & 2 \\
Ernani Mendes Botelho & USP & 2 \\
Elizete Aparecida de Magalhães & UFVJM & 2 \\
Suely de Fátima Ramos Silveira & UFV & 2 \\
Luciano Gomes dos Resis & UNIUBE & 2 \\
Ely Célia Corbari & UFPR & 2 \\
Wilson Gerik & UFPR & 2 \\
Altair Borget & UFSC & 1 \\
Daniel Cerqueira Ribeiro & UnB & 1 \\
Umbelina Cravo Teixeira Lagioia & UFPE & 1 \\
Marcos Laffin & UFSC & 1 \\
Marcia Zanievick & UFSC & 1 \\
Demais autores & Outras & 1 \\
\hline Font Dados & &
\end{tabular}

Fonte: Dados da pesquisa (2011).

Sobre a instituição à qual os autores estão filiados, em alguns casos, foi necessária uma pesquisa na Plataforma Lattes, por não constar no artigo. Na Tabela 8, estão classificados os trabalhos por sexo.

Tabela 8 - Distribuição dos trabalhos por sexo

\begin{tabular}{lcc}
\hline SEXO & Frequência & Percentual \\
\hline Homens & 91 & 65 \\
Mulheres & 48 & 35 \\
\hline Total & 139 & $100 \%$ \\
\hline Fonte: Dados da pesquisa (2011)
\end{tabular}

Verifica-se que pesquisadores homens publicaram maior número de trabalhos sobre custo no setor público.

$\mathrm{Na}$ Tabela 9, evidenciou-se uma classificação por ordem das instituições às quais os autores estão vinculados. Essa ordem, então, é individual e representa quais instituições, por autor, têm maior frequência na publicação dos trabalhos.

A UnB desponta em primeiro lugar com sete trabalhos. A UFPR aparece em segundo lugar na ordem de publicação considerando individualmente os pesquisadores. Em terceiro lugar, a USP e a UFPE, com cinco publicações. Em quarto lugar, a UEM e a UFSC, com quatro publicações cada. Em quinto lugar UFC, UFMG, UFV e UERJ. Em sexta posição, juntas, FGV, UFVJM, UNIUBE e UFBA.

Tabela 9 - Classificação por frequência de instituições

\begin{tabular}{|c|c|c|c|c|c|c|}
\hline \multirow[b]{2}{*}{ INSTITUIÇÕES } & \multicolumn{2}{|c|}{ EnANPAD e EnAPG } & \multicolumn{2}{|c|}{ CBC } & \multicolumn{2}{|c|}{ USP } \\
\hline & Trabalhos & Percentual & Trabalhos & Percentual & Trabalhos & Percentual \\
\hline UFPR & & & 6 & 18,75 & & \\
\hline UEM & 4 & 12,12 & & & & \\
\hline UnB & 4 & 12,12 & & & 3 & 33,33 \\
\hline UFSC & & & 3 & 9,38 & 1 & 11,11 \\
\hline UFC & 3 & 9,09 & & & & \\
\hline UFMG & 3 & 9,09 & & & & \\
\hline USP & 2 & 6,06 & 2 & 6,25 & 1 & 11,11 \\
\hline
\end{tabular}


Custos na Administração Pública: revisão focada na publicação de artigos científicos a partir da...

\begin{tabular}{|c|c|c|c|c|c|c|}
\hline FGV & 2 & 6,06 & & & & \\
\hline UFPE & 2 & 6,06 & 2 & 6,25 & 1 & 11,11 \\
\hline UFV & 2 & 6,06 & & & 1 & 11,11 \\
\hline UFVJM & 2 & 6,06 & & & & \\
\hline UNIUBE & & & 2 & 6,25 & & \\
\hline UERJ & & & 2 & 6,25 & 1 & 11,11 \\
\hline EFBA & & & 2 & 6,25 & & \\
\hline ULBRA & & & & & 1 & 11,11 \\
\hline Outras & 7 & 21,21 & 7 & 21,87 & & \\
\hline Não identificadas & 2 & 6,06 & 6 & 18,75 & & \\
\hline Total & 33 & $100 \%$ & 32 & $100 \%$ & 9 & $100 \%$ \\
\hline
\end{tabular}

Várias instituições aparecem na sequência com apenas um trabalho de um autor, mas que representou 21\%, considerando em separado os eventos CBC e da ANPAD. Outras oito não foram identificadas na pesquisa, mesmo verificando os nomes na Plataforma Lattes.

Sobre técnicas de coleta de dados e métodos de pesquisa utilizados nas Tabelas $10 \mathrm{e}$ 11, demonstram-se os principais. Esse item foi o mais difícil pelo fato de alguns trabalhos não apresentarem resumo ou ter apresentado de modo não claro no texto os métodos e as técnicas empregados. Verificou-se a utilização de mais de uma técnica em um mesmo trabalho. Desse modo, o somatório na Tabela 10 representa todas as técnicas, e não o total de trabalhos.

Tabela 10 - Técnicas de coleta de dados utilizados nos trabalhos

\begin{tabular}{lcccccc}
\hline & \multicolumn{2}{c}{$\begin{array}{c}\text { EnANPAD e EnAPG } \\
\text { TÉCNICAS }\end{array}$} & Trabalhos & Percentual & EnANPAD e EnAPG & \multicolumn{2}{c}{$\begin{array}{c}\text { EnANPAD e EnAPG } \\
\text { Trabalhos }\end{array}$} & $\begin{array}{c}\text { Percentual } \\
\text { Trabalhos }\end{array}$ & Percentual \\
\hline Análise de textos e & & & & & & \\
$\quad$ Documentos & 6 & 33 & 14 & 35 & 5 & 56 \\
Entrevistas e observação & 5 & 28 & 12 & 30 & 2 & 22 \\
Modelos e aplicações & 4 & 22 & 8 & 20 & 1 & 11 \\
Questionários & 3 & 17 & 6 & 15 & 1 & 11 \\
\hline Soma das técnicas & 18 & $100 \%$ & 40 & $100 \%$ & 9 & $100 \%$ \\
\hline
\end{tabular}

Fonte: Dados da pesquisa (2011).

A técnica de análise documental foi a mais utilizada, seguida de entrevistas e observação. A técnica de aplicações de modelos foi a terceira mais usada e representou, por exemplo, aplicação de modelo de sistema de custeio e sistemática de cálculo de custo por aluno do Tribunal de Contas da União, bem como o cálculo do resultado econômico e custo de oportunidade. Os questionários foram a quarta técnica mais utilizada, o que coincidiu com a estratégia de pesquisa quantitativa. Apenas no Congresso de Controladoria e Contabilidade as técnicas Modelos e Aplicações e Questionários foram igualmente a terceira mais usada pelos autores.

Tabela 11 - Estratégias de pesquisa

\begin{tabular}{lcccccc}
\hline & EnANPAD e EnAPG & \multicolumn{2}{c}{ CBC } & \multicolumn{2}{c}{ USP } \\
ESTRATÉGIAS & Trabalhos & Percentual & Trabalhos & Percentual & Trabalhos & Percentual \\
\hline Qualitativa & 10 & 77 & 17 & 53 & 5 & 55 \\
Quantitativa & 3 & 23 & 15 & 47 & 4 & 45 \\
\hline Total & 13 & $100 \%$ & 32 & $100 \%$ & 9 & $100 \%$ \\
\hline
\end{tabular}

Fonte: Dados da pesquisa (2011). 
A maioria dos autores optou pela estratégia qualitativa, e como métodos mais empregados o estudo de caso e a análise de conteúdo. Na estratégia quantitativa, o método para tratamento dos dados mais utilizado foi a estatística descritiva.

\subsection{Conteúdo da Produção Científica}

Na Tabela 12, apresentam-se os métodos de custeio. Procurou-se saber quais foram os mais discutidos, mais comentados ou mesmo resultantes de achados de pesquisa:

Tabela 12 - Métodos de Custeio

\begin{tabular}{lccccccccccccc}
\hline \multicolumn{1}{c}{ ÁREA } & $\mathbf{2 0 0 0}$ & $\mathbf{2 0 0 1}$ & $\mathbf{2 0 0 2}$ & $\mathbf{2 0 0 3}$ & $\mathbf{2 0 0 4}$ & $\mathbf{2 0 0 5}$ & $\mathbf{2 0 0 6}$ & $\mathbf{2 0 0 7}$ & $\mathbf{2 0 0 8}$ & $\mathbf{2 0 0 9}$ & $\mathbf{2 0 1 0}$ & Total & \% \\
\hline Custeio ABC & 1 & 1 & & 3 & 3 & 2 & 4 & 3 & 4 & 2 & 1 & 24 & 44,44 \\
Custeio por Absorção & & & & 1 & & 2 & & 1 & & & 1 & 5 & 9,26 \\
Custeio Direto ou Variável & 1 & & & & & 1 & & 1 & 1 & & & 4 & 7,41 \\
Não definido & 1 & & 1 & & 7 & 1 & 5 & 2 & 1 & 1 & 2 & 21 & 38,89 \\
\hline Total & 3 & 1 & 1 & 4 & 10 & 6 & 9 & 7 & 6 & 3 & 4 & 54 & $100 \%$ \\
\hline
\end{tabular}

Fonte: Dados da pesquisa (2011).

O método de custeio ABC com 44,44\%, como tema ou discussão nos trabalhos, é o primeiro entre os mais discutidos. Em segundo, aparece o custeio por Absorção. Destaca-se que também $38,89 \%$ dos trabalhos não tiveram por escopo discutir ou comentar sobre os métodos de custeio no setor público. Os anos de 2004, 2005, 2006, 2007 e 2008 foram os que mais obtiveram publicações, ao passo que 2001 e 2002 foram os únicos anos em que as publicações foram em número de apenas um.

Com relação à orientação dada pelos autores quanto ao melhor método de custeio ou ao sistema mais adequado às organizações públicas, procurou-se ler as conclusões e recomendações de todos os trabalhos. Em cinco artigos, houve a orientação do sistema $\mathrm{ABC}$ para hospitais públicos, e um artigo orientou o mesmo sistema para as universidades federais brasileiras, dois artigos com aplicação no Banco Central do Brasil, um trabalho para a educação infantil, outro para um sistema de coleta de lixo municipal, um artigo orientou o sistema para os serviços públicos e outro para utilização no orçamento da administração pública. Desse modo, o método ABC totalizou 12 artigos como o mais adequado e representou 22,22\% do total de trabalhos publicados nos eventos. Esse resultado coadunou-se com o referencial teórico.

O Gráfico 1 evidencia os trabalhos divididos em temas ou abordagens.

\section{Gráfico 1 - Gráfico dos temas ou abordagens dos artigos de custos no setor público}

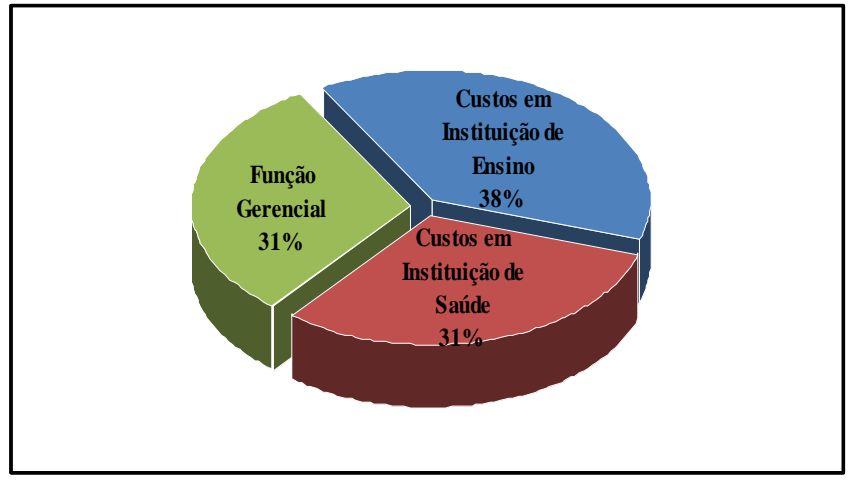

Fonte: Dados da pesquisa (2011). 
Para identificar essas abordagens, foi realizada uma pesquisa nos títulos, palavraschave, resumo e, quando necessário, em todo o artigo. As três grandes abordagens identificadas foram: Custos em Instituições de Ensino, Custos em Instituições de Saúde e Função Gerencial, com predomínio da primeira.

Do total geral de trabalhos, 38\% abordaram custos em instituições de ensino, $31 \% \mathrm{em}$ custos em instituições de saúde, e igual resultado na função gerencial. Dos cinco artigos em custos em instituições de ensino, dois apresentaram metodologia de custo por aluno.

\section{Considerações Finais}

O objetivo principal da pesquisa foi dimensionar e revisar de forma descritiva a produção científica nos anais eletrônicos dos eventos brasileiros da Associação Nacional de Pós-Graduação e Pesquisa em Administração (ANPAD), Associação Brasileira de Custos (ABC), e do Congresso de Controladoria e Contabilidade da Universidade de São Paulo (USP). Para selecionar os trabalhos e sua análise posterior optou-se por considerar aqueles que contivessem, no título, no resumo ou na introdução, as palavras-chave: "custos", "custo", "sistema de custos", "Contabilidade de Custos", "administração pública" e "setor público".

Considerando os procedimentos e o período, foram selecionados 54 trabalhos publicados on-line que constituíram os dados da pesquisa. Constatou-se que o tema Custos no Setor Público é pouco abordado nos eventos da ANPAD e no evento da USP, o que corrobora pesquisas anteriores que foram mais generalizadas.

O Congresso Brasileiro de Custos apresenta grande contribuição à pesquisa brasileira de custos, tendo em vista ser específico para essa área. A maioria dos temas de Contabilidade de Custos é abordada de forma prática em várias instituições, tanto públicas quanto privadas. Nos últimos 10 anos foram apresentados, em média, 300 trabalhos por ano, distribuídos em 16 áreas temáticas, todas relacionadas à Contabilidade de Custos.

No Congresso da USP de Controladoria e Contabilidade, no período de 2004 a 2010, cujas publicações estão disponíveis para consulta on-line, foram pesquisados 699 trabalhos publicados, os quais compõem o universo da pesquisa. Foram publicados em média 100 trabalhos por ano, distribuídos em cinco áreas temáticas, cujo foco principal é Ciências Contábeis.

Ao considerar critérios pré-estabelecidos, concluiu-se, quanto ao perfil dos artigos, que os anais do evento EnANPAD têm maior número de publicações sobre o tema do que os anais do EnAPG, e os anos de maior número de publicações foram 2004 e 2006. A área temática de maior frequência escolhida é Contabilidade Gerencial e Controladoria.

Verificou-se que predominam pesquisadores homens e o maior número é de publicações com quatro autores para os eventos da ANPAD. No Congresso Brasileiro de Custos e no Congresso da USP de Controladoria e Contabilidade, a maior frequência é de dois autores. Wellington Rocha é o pesquisador com maior número de trabalhos, e as instituições UnB e UFPR têm maior número de publicações. As técnicas de pesquisa mais utilizadas são a análise documental e entrevistas e, quanto à estratégia escolhida, a abordagem qualitativa é a mais frequente. 
Quanto ao conteúdo dos trabalhos, o método de custeio ABC é o mais discutido, bem como é o mais orientado para o setor público, o que se coaduna com o referencial teórico. Desse modo, a pesquisa reafirmou, para a prática contábil do setor público, a utilidade desse método. A abordagem predominante é custos para instituições de ensino público e instituições hospitalares.

De acordo com os fatores de limitação da pesquisa, os resultados não podem ser generalizados, mas demonstram tendências.

\section{Referências}

ALMEIDA, André G. de; BORBA, José A.; FLORES, Luiz C. S. A utilização das informações de custos na gestão da saúde pública: um estudo preliminar em secretarias municipais de saúde do estado de Santa Catarina. Revista de Administração Pública, Rio de Janeiro, v. 43, p. 579-607, maio/jun. 2009.

ALONSO, Marcos. Custos no serviço público. Revista do Serviço Público. Brasília, ano 50, n. 1, p. 37-63, jan./mar. 1999.

ATKINSON, Anthony A. et al. Contabilidade Gerencial. 2. ed. São Paulo: Atlas, 2008.

BRASIL. Constituição (1988). Constituição da República Federativa do Brasil: 1988. Brasília: Senado, 1998.

BRASIL. Lei Complementar n. 101, de 4 de maio de 2000. Estabelece normas de finanças públicas voltadas para a responsabilidade na gestão fiscal e dá outras providências. Diário Oficial da República Federativa do Brasil, Brasília, 5 de maio de 2000.

BRASIL. Lei n. 4.320, de 17 de março de 1964. Estatui normas de direito financeiro para elaboração e controle dos orçamentos e balanços da União, dos Estados, dos Municípios e do Distrito Federal. Disponível em: 〈http://www.stn.fazenda.gov.br/legislacao/leg_contabilidade.asp >. Acesso em 10 nov. 2011.

BRASIL. Ministério do Planejamento, Orçamento e Gestão. Instruções para avaliação da gestão pública - 2008/2009. Brasília: MP, SEGES, 2008.

BRASIL. Secretaria do Tesouro Nacional e Secretaria de Orçamento Federal. Portaria Interministerial n. 1, de 20 de junho de 2011. Aprova as Partes I - Procedimentos Contábeis Orçamentários e VIII - Demonstrativo de Estatística de Finanças Públicas, da $4^{\mathrm{a}}$ edição do Manual de Contabilidade Aplicada ao Setor Público - MCASP, e dá outras providências. Brasília, DF. 2011. Disponível em: < http://www.stn.fazenda.gov.br/legislacao/leg_contabilidade.asp >. Acesso em 30 nov. 2011.

BRASIL. Secretaria do Tesouro Nacional. Portaria n. 406, de 20 de junho de 2011. Aprova as Partes II - Procedimentos Contábeis Patrimoniais, III - Procedimentos Contábeis Específicos, IV - Plano de Contas Aplicado ao Setor Público, V - Demonstrações Contábeis Aplicadas ao Setor Público, VI - Perguntas e Respostas e VII - Exercício Prático, da $4^{\mathrm{a}}$ edição do Manual de Contabilidade Aplicada ao Setor Público, e dá outras providências. Brasília, DF. 2011. Disponível em: <http://www.stn.fazenda.gov.br/legislacao/leg_contabilidade.asp $>$. Acesso em 30 nov. 2011. 
BRASIL. Secretaria do Tesouro Nacional. Portaria n. 828, de 14 de dezembro de 2011. Altera o prazo de implementação do Plano de Contas Aplicado ao Setor Público e dá outras providências. Brasília, $\quad$ DF. 2011. Disponível em: <http://www.stn.fazenda.gov.br/legislacao/download/contabilidade/PortSTN_828_20111214. pdf $>$. Acesso em 3 fev. 2012.

CONSELHO FEDERAL DE CONTABILIDADE (CFC). Aprova o Apêndice II da Resolução CFC n. 750/93 sobre os Princípios Fundamentais de Contabilidade. Resolução CFC n. 1.111/07. CFC, 2007. Disponível em: <http://www.cfc.org.br/sisweb/sre/Default.aspx $>$. Acesso em 6 dez. 2011.

BRASIL. NBC T 16 - Normas Brasileiras de Contabilidade Aplicadas ao Setor Público. Disponível em: <http://www.cfc.org.br/sisweb/sre/Default.aspx >. Acesso em: 6 dez. 2011.

CHAN, James L. As NICSPS e a contabilidade governamental de países em desenvolvimento. Revista de Educação e Pesquisa em Contabilidade. Brasília, n. 1, p. 1 - 17, jan./abr. 2010.

CRUZ, Flavio da; PLATT NETO, Orion Augusto. Contabilidade de custos para entidades estatais: metodologia e casos simulados. Ed. Fórum: Belo Horizonte, 2007.

FELIX, Claudia L. et al. Em busca da harmonização das normas contábeis para o setor público: uma comparação entre balanços patrimoniais segundo a lei 4320/64 e a IPSAS 1. In: ENCONTRO DE ADMINISTRAÇÃO PÚBLICA E GOVERNANÇA, 3., 2008, Salvador/BA. Anais... Salvador: ANPAD, 2008.

GIL, Antonio C. Como elaborar projetos de pesquisa. 4. ed. São Paulo: Atlas, 2008.

GOMES, Carlos A. S. et al. Produção científica em contabilidade pública: uma análise dos artigos apresentados no EnANPAD e o Congresso USP de Controladoria e Contabilidade no período 2004 - 2007. In: ENANPAD, 32., 2008, Rio de Janeiro/RJ Anais... Rio de Janeiro: ANPAD, 2008.

LIMA, Diana V. de; CASTRO, Robson G. de. Contabilidade Pública: integrando União, Estados e Municípios (SIAF e SIAFEM). 2. ed. São Paulo: Atlas, 2003.

LUQUE, Carlos A. et al. O processo orçamentário e a apuração de custos de produtos e serviços no setor público do Brasil. Revista do Serviço Público, Brasília, n. 3, p. 309-331, jul./set. 2008.

MACHADO, Nelson. Sistema de informação de custo: diretrizes para integração ao orçamento público e à contabilidade governamental. 2002. 221 p. Tese (Doutorado em Controladoria e Contabilidade) - Faculdade de Economia, Administração e Contabilidade, Universidade de São Paulo, São Paulo, 2002.

MARTINS, Elizeu. Contabilidade de Custos. 9. ed. São Paulo: Atlas, 2006.

MARTINS, Gilberto de A.; THEÓPHILO, Carlos R. Metodologia da investigação científica para ciências sociais aplicadas. São Paulo: Atlas, 2007.

MAUSS, Cézar V.; SOUZA, Marcos A. de. Gestão de custos aplicada ao setor público: modelo para mensuração e análise da eficiência e eficácia governamental. São Paulo: Atlas, 2008. 
MUTULA, S.; WAMUKOYA, J. M. Public sector information management in east and southern Africa: Implications for FOI, democracy and integrity in government. International Journal of Information Management [S.I.], n. 5, p. 333-341, 2009.

REIS, Luciano G. dos et al. A pesquisa brasileira em contabilidade do setor público: uma análise após a implementação da lei de responsabilidade fiscal. Revista de Informação Contábil. Recife, n. 1, p. 89-101, set. 2007.

ROSA, Maria B. Contabilidade do setor público: de acordo com as inovações das normas brasileiras de contabilidade. São Paulo: Atlas, 2011.

SILVA, Lino M. da. Contabilidade governamental: um enfoque administrativo da nova contabilidade pública. 9. ed. São Paulo: Atlas, 2011.

SILVA, Moacir M. da et al. Lei de responsabilidade fiscal para os municípios: uma abordagem prática. 2. ed. São Paulo: Atlas, 2007.

SLOMSKI, Valmor. Controladoria e governança na gestão pública. São Paulo: Atlas, 2007.

SÖTHE, Ari et al. Sistema de custeio na administração pública municipal: uma aplicação da gestão de custos na Secretaria Municipal de Agricultura e Meio Ambiente de São João do Oeste - SC. Revista ABCustos. Rio Grande do Sul, n. 2, p. 62-83, maio/ago. 2010.

SOUZA, Antônio A. de et al. As implicações da adoção dos sistemas de custeio para a administração pública gerencial. In: Encontro de Administração Pública e Governança, 2., 2006, São Paulo/SP.Anais... São Paulo: ANPAD, 2006.

UNIVERSIDADE DE SÃO PAULO (USP). Congresso da USP de Controladoria e Contabilidade-Anais 2001 a 2010. Disponível em: 〈http://www.congressousp.fipecafi.org > Acesso em 5 jun. 2011.

VERGARA, Sylvia C. Projetos e relatórios de pesquisa em administração. 11. ed. São Paulo: Atlas, 2009. 